\title{
Bio-inspired bimetallic enzyme mimics as bioorthogonal catalysts for enhanced bacterial capture and inhibition
}

Jingsheng Niu, ${ }^{1,2}$ Chuanqi Zhao, ${ }^{* 1,2}$ Chun Liu, ${ }^{1,2}$ Jinsong Ren, ${ }^{1,2}$ and Xiaogang $\mathrm{Qu}^{*, 1,2}$

${ }^{1}$ Laboratory of Chemical Biology and State Key Laboratory of Rare Earth Resource Utilization, Changchun Institute of Applied Chemistry, Chinese Academy of Sciences Changchun, Jilin 130022, P. R. China.

${ }^{2}$ University of Science and Technology of China, Hefei, Anhui 230026, P. R. China. 


\section{Materials}

Potassium bromide $(\mathrm{KBr})$, Copper chloride dehydrate $\left(\mathrm{CuCl}_{2} \cdot 2 \mathrm{H}_{2} \mathrm{O}\right)$, Ascorbic acid (AA), Polyethylene glycol ( $\mathrm{Mw}$ 600) were purchased from Aladdin Reagent (Shanghai, China). Palladium chloride $\left(\mathrm{PdCl}_{2}\right)$ was purchased from TCI (Shanghai) Development Co., Ltd. 3, 3' , 5, 5' -tetramethylbenzidine (TMB) was purchased from BBI (Ontario, Canada). Other reagents and solvents were achieved from Beijing Chemicals (Beijing, China). All other regents were of analytical reagent grade and all the chemicals used without further purification. Ultrapure water $\left(18.2 \mathrm{M} \Omega \cdot \mathrm{cm}^{-1}\right.$, Millpore Co., USA) was used throughout the experiment.

\section{Measurements}

SEM images were obtained on a Hitachi S-4800 FESEM at a working voltage of 10 $\mathrm{kV}$ and working current of $10 \mu \mathrm{A}$. TEM measurements were carried out on a TECNAI G2 equipped with EDS at $200 \mathrm{kV}$. The UV-Vis absorption spectra were recorded using a JASCO V550 UV/Visible spectrophotometer (JASCO International Co., LTD., Tokyo, Japan). Fluorescence spectra were measured on a JASCO FP-6500 spectrofluorometer equipped with a temperature-controlled water bath. All the spectra were recorded in a $1.0 \mathrm{~cm}$ path length cell. The Zeta potentials and dynamic light scatting (DLS) of all examples were measured in a Zetasizer 3000HS analyzer (Malvern Instruments).

\section{Synthesis of PdCu nanoparticles.}

The Sea urchin-like $\mathrm{PdCu}$ (PdCu-Urchin) with zigzag-shaped branches was synthesized by a one-pot method according to the previous literature with a little modification. ${ }^{1}$ Typically, about $138 \mathrm{mg}$ of $\mathrm{KBr}$ solid was dissolved in $5 \mathrm{~mL}$ Polyethylene glycol solution ( $\mathrm{Mw} 600,0.01 \mathrm{wt} \%$ ) under ultrasound, and then added $1.25 \mathrm{~mL} \mathrm{H}_{2} \mathrm{PdCl}_{4}(20 \mathrm{mM}), 0.5 \mathrm{~mL} \mathrm{CuCl}_{2} \cdot 2 \mathrm{H}_{2} \mathrm{O}(20 \mathrm{mM})$ and $1 \mathrm{~mL} \mathrm{HCl}$ solution $(6$ $\mathrm{mM})$ under continuous ultrasound. Subsequently, $1.0 \mathrm{~mL}$ ascorbic acid solution $(0.1$ $\mathrm{mM}$ ) was added, and the mixture was allowed to react in an oil bath at $95^{\circ} \mathrm{C}$ for 30 minutes without any interference. Finally, $\mathrm{PdCu}$ nanoparticles were obtained by centrifugation at $6000 \mathrm{rpm}$, washed with water and ethanol, and stored in ethanol for further use.

In order to compare the ability for capturing bacteria, Nano flower-like $\mathrm{PdCu}$ (PdCu-Flower) was also synthesized. Similar to the sea urchin-like PdCu synthesis method except that the reaction requires stirring.

\section{Peroxidase-like Catalytic Activity of PdCu-Urchin}

The color change of peroxidase-like PdCu-Urchin towards TMB was photographed at room temperature after $5 \mathrm{~min}$ of co-incubation. The final concentrations of TMB, $\mathrm{H}_{2} \mathrm{O}_{2}$, and $\mathrm{PdCu}$ were $1 \mathrm{mM}, 25 \mathrm{mM}$, and $\sim 50 \mu \mathrm{g} \cdot \mathrm{mL}^{-1}$, respectively. The reaction time was $5 \mathrm{~min}$. The buffer solution was PBS with a $\mathrm{pH}$ value of 4 . The reactions were monitored in the time scan mode at $652 \mathrm{~nm}$ for TMB using a JASCO V550 UV/Visible spectrophotometer. 


\section{Click Catalytic Activity of PdCu-Urchin}

Click reaction of 3-azido-7-hydroxycoumarin 1 and phenylacetylene $\mathbf{2}$ was carried out to evaluate the catalytic efficiency of PdCu-Urchin. Mixed PdCu-Urchin (100 $\mu \mathrm{g} / \mathrm{mL}$ ), $80 \mu \mathrm{M}$ 3-azido-7-hydroxycoumarin (4 $\mathrm{mM}$ in DMSO) and phenylacetylene in water at $37^{\circ} \mathrm{C}$. After a period of time, the mixture was centrifuged to remove the catalyst. The fluorescence change of the supernatant was measured with a fluorescence spectrometer.

\section{Synthesis of precursor molecules 4 and 5}

Synthesis of precursor chemical substrate molecules in this study according to previous report. ${ }^{2-3}$
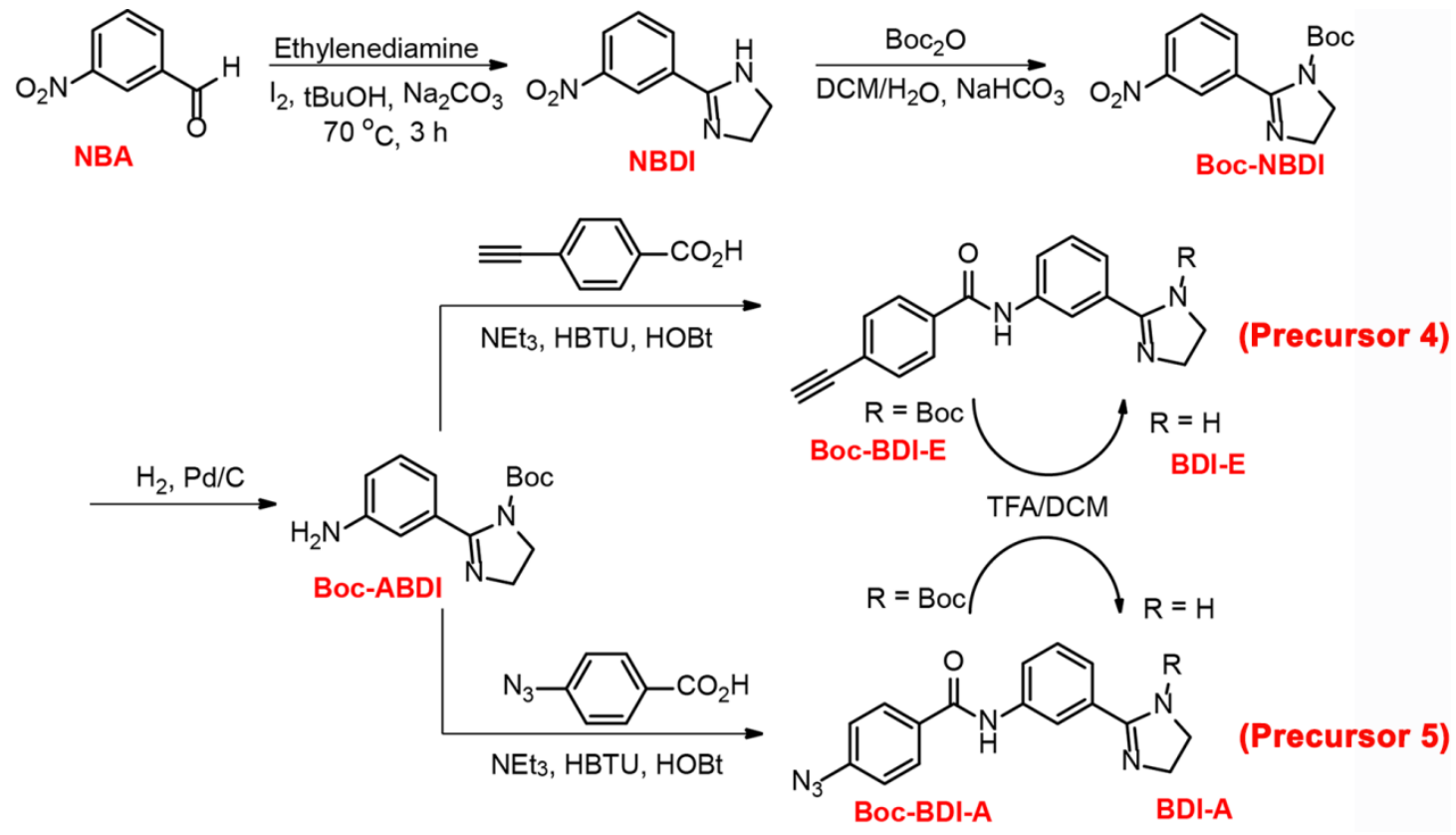

\section{I . N-boc-2-(3-nitrophenyl)-4,5-dihydro-1H-imidazole (Boc-NBDI) synthesis}

\section{process.}

Combined 3-nitrobenzaldehyde (3.02 g, $20 \mathrm{mmol})$ and ethylenediamine $(1.47 \mathrm{~mL}$, $22 \mathrm{mmol})$ in tert-butanol $(100 \mathrm{~mL})$, and stirred the mixture for 30 minutes. $\mathrm{Na}_{2} \mathrm{CO}_{3}$ $(6.36 \mathrm{~g}, 60 \mathrm{mmol})$ and $\mathrm{I}_{2}(6.34 \mathrm{~g}, 25 \mathrm{mmol})$ were added to the mixture, and then the reaction temperature was increased to $70^{\circ} \mathrm{C}$ for $3 \mathrm{~h}$. The solution was cooled, and saturated aqueous $\mathrm{Na}_{2} \mathrm{SO}_{3}$ was added to quench the excess $\mathrm{I}_{2}$ to obtain a pale yellow mixture. Removed solvent under reduced pressure. $100 \mathrm{~mL}$ Ethyl acetate was added to the mixture, sonicated and filtered to remove insoluble materials. Washed the solution with saturated aqueous $\mathrm{Na}_{2} \mathrm{SO}_{3}(100 \mathrm{~mL})$, brine $(100 \mathrm{~mL})$, and dried over $\mathrm{Na}_{2} \mathrm{SO}_{4}$. Removed the ethyl acetate to give a pale yellow solid under reduced pressure, and redissolved in $50 \mathrm{~mL}$ DCM. The $\mathrm{DCM}$ solution was cooled to $0^{\circ} \mathrm{C}$, and $\mathrm{Boc}_{2} \mathrm{O}$ ( $6.6 \mathrm{~g}$, excess) was added to the solution together with $50 \mathrm{~mL}$ aqueous $\mathrm{NaHCO}_{3}$. The two-layer mixture was gradually warmed to room temperature, stirred overnight. The DCM layer was separated, dried with $\mathrm{Na}_{2} \mathrm{SO}_{4}$ and evaporated to give a crude product, 
which was further purified by column chromatography (silica, ethyl acetate/hexane $1: 2$ to $1: 1)$ to give a pale yellow oily product.

\section{II . N-boc-2-(3-aminophenyl)-4,5-dihydro-1H-imidazole (Boc-ABDI) synthesis}

\section{process.}

Dissolved the nitro product $\mathrm{N}$-Boc-2-(3-aminophenyl)-4,5-dihydro- $1 \mathrm{H}$-imidazole $(1.2 \mathrm{~g}, 4.1 \mathrm{mmol})$ from the previous step in $20 \mathrm{~mL}$ THF or ethyl acetate. $150 \mathrm{mg} 10 \%$ $\mathrm{Pd} / \mathrm{C}$ was added. Reaction vessel was deoxygenated and added hydrogen via a balloon. Reaction was overnight at room temperature. Resulting mixture was filtered and evaporated and then obtained the pure product as a light white solid.

\section{III . Synthesis process of compound 4 (BDI-E) $\cdot$ TFA.}

Mixed $N$-Boc-2-(3-aminophenyl)-4,5-dihydro- $1 H$-imidazole (previous step) ( $0.78 \mathrm{~g}$, $3.0 \mathrm{mmol})$ and 4-alkynylbenzoic acid (0.54 g, $3.3 \mathrm{mmol})$, HBTU (1.37) g, $3.6 \mathrm{mmol})$, HOBt $(0.36 \mathrm{~g}, 2.7 \mathrm{mmol})$ in $15 \mathrm{~mL}$ DMF. Added triethylamine $(0.84 \mathrm{~mL}, 6.0 \mathrm{mmol})$ to the solution, and kept the reaction at room temperature overnight. Poured the solution into $125 \mathrm{~mL}$ water and stirred for 5 minutes, then filtered to collect the precipitate. Redissolved the solid in $50 \mathrm{~mL}$ ethyl acetate and washed twice with aqueous $\mathrm{NaOH}(1 \mathrm{M}, 50 \mathrm{~mL})$ and once with $50 \mathrm{~mL}$ brine. Dried the solution over $\mathrm{Na}_{2} \mathrm{SO}_{4}$ and evaporated to give the crude, Boc-protected product, and purified by column chromatography (silica, ethyl acetate/hexane 1:2 to 1:1). The purified product was deprotected with TFA $(50 \% \mathrm{v} / \mathrm{v}$ in DCM, $10 \mathrm{~mL})$ for 3 hours at $0^{\circ} \mathrm{C}$. The TFA and DCM were removed under reduced pressure. Washed the residue was with ether and dried to obtain the product in the form of the TFA salt as a pale yellow solid.

\section{IV . Synthesis process of compound $5(B D I-A) \cdot T F A$.}

The synthesis of 5.TFA was similar to the synthesis of 4.TFA, using $\mathrm{N}$-Boc-2-(3-aminophenyl)-4,5-dihydro-1 $H$-imidazole and replaced 4-alkynylbenzoic acid with 4-azidobenzoic acid.

\section{Morphology Observation of Bacteria}

For SEM images of bacteria, after the material absorbing bacteria for 30 minutes, the bacteria cultured at $37{ }^{\circ} \mathrm{C}$ were harvested by centrifugation at $3500 \mathrm{rpm}$ for $5 \mathrm{~min}$. They were washed with PBS and then fixed in PBS containing $4 \%$ formaldehyde for $15 \mathrm{~min}$. The cells were further washed with DI water, followed by dehydration using a series of ethanol $(30 \%, 50 \%, 70 \%, 85 \%, 95 \%$, and $100 \%)$. The bacteria in $100 \%$ ethanol were finally dried in a vacuum drying chamber at room temperature. Before imaging, the bacteria were sputter-coated with platinum.

\section{Histology}

For histology, the mice were sacrificed, and the wound tissues were harvested after 3 days of therapy. The wound tissues treated with different nanoparticles were fixed in neutral buffered formalin, processed routinely into paraffin, sectioned into $\sim 4 \mu \mathrm{m}$, and stained with H\&E. The histology was performed in the college of Basic Medical 
Sciences of Jilin University. The samples were examined by an Olympus BX-51 microscope in bright field.
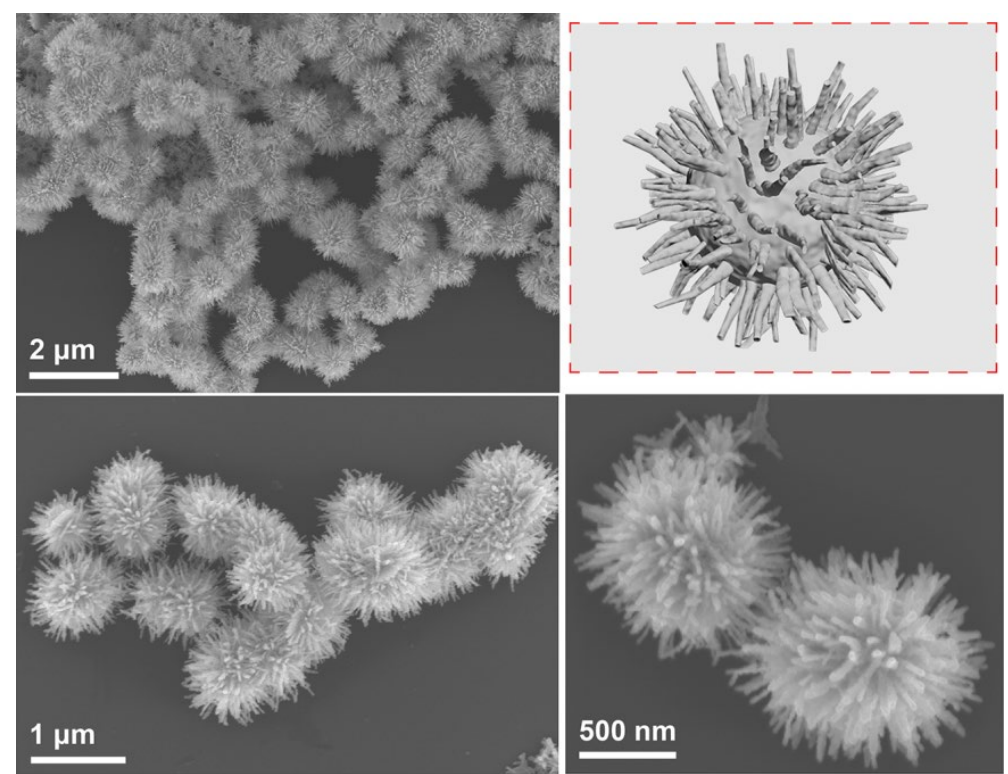

Figure S1. SEM images of PdCu-Urchin under different magnifications.
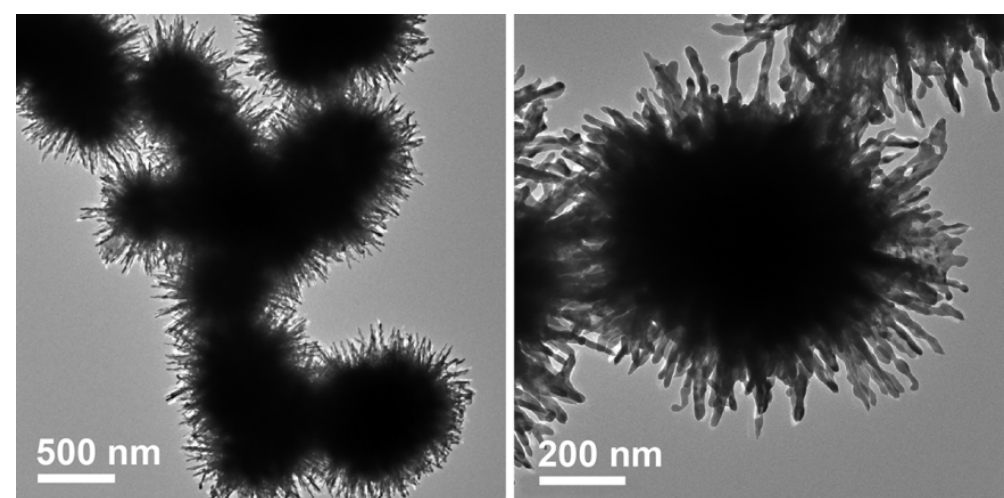

Figure S2. TEM images of $\mathrm{PdCu}-U r c h i n$ under different magnifications. 

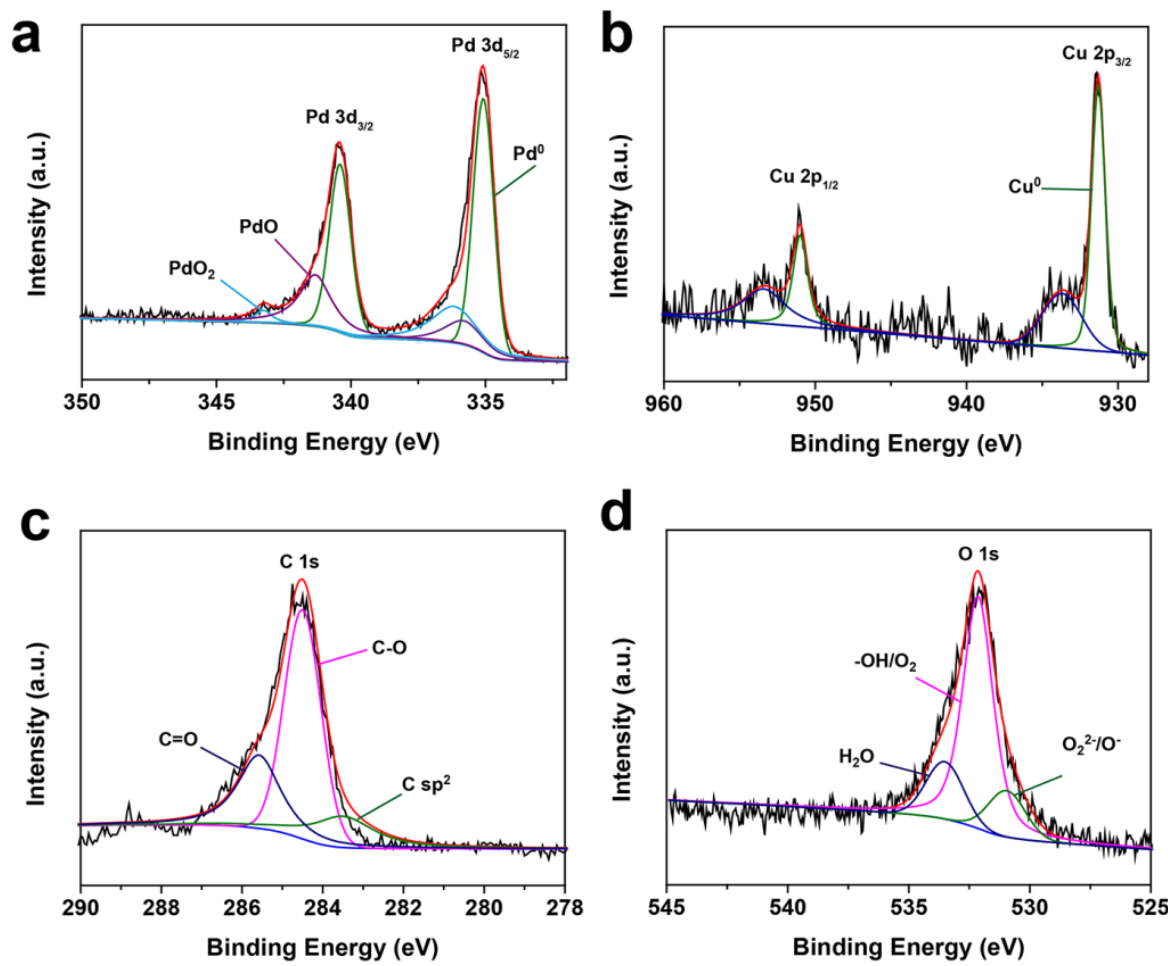

Figure S3. XPS spectra of (a) Pd 3d, (b) Cu 2p, (c) C1s, (d) O1s of PdCu-Urchin. 

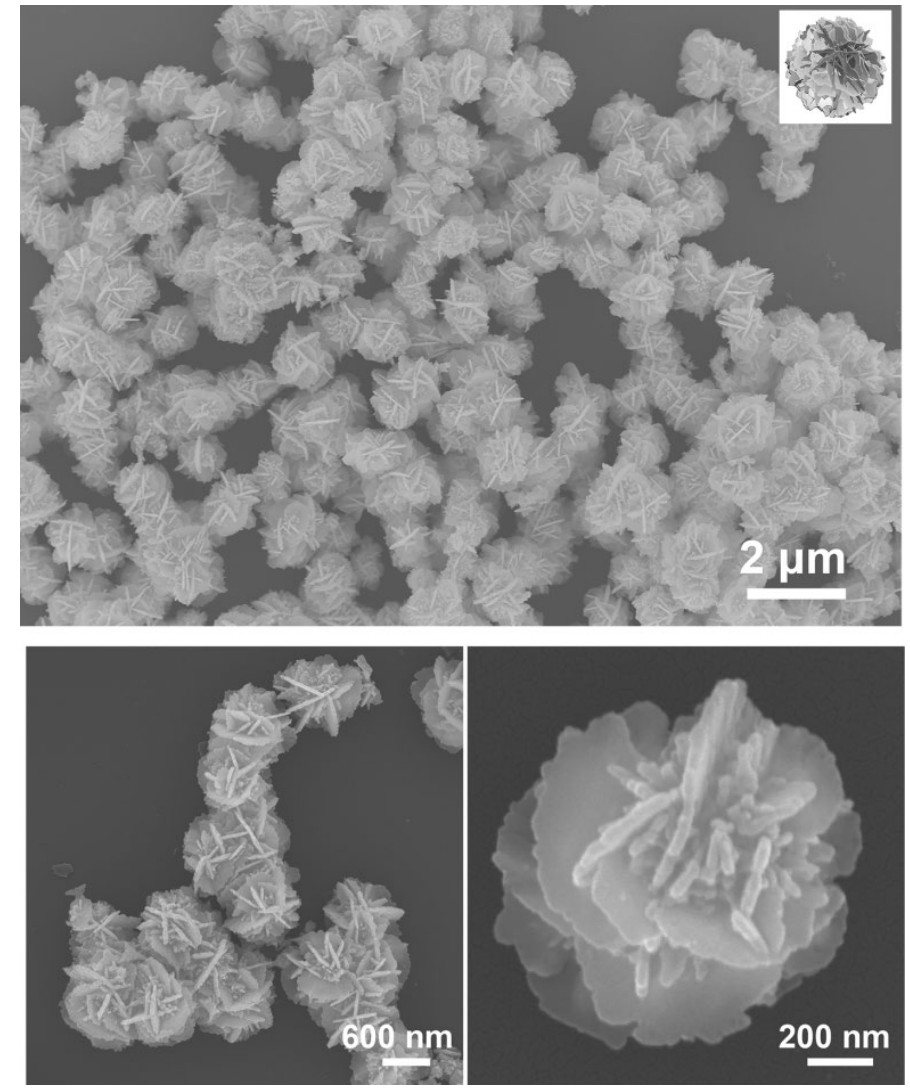

Figure S4. SEM images of PdCu-Flower under different magnifications.
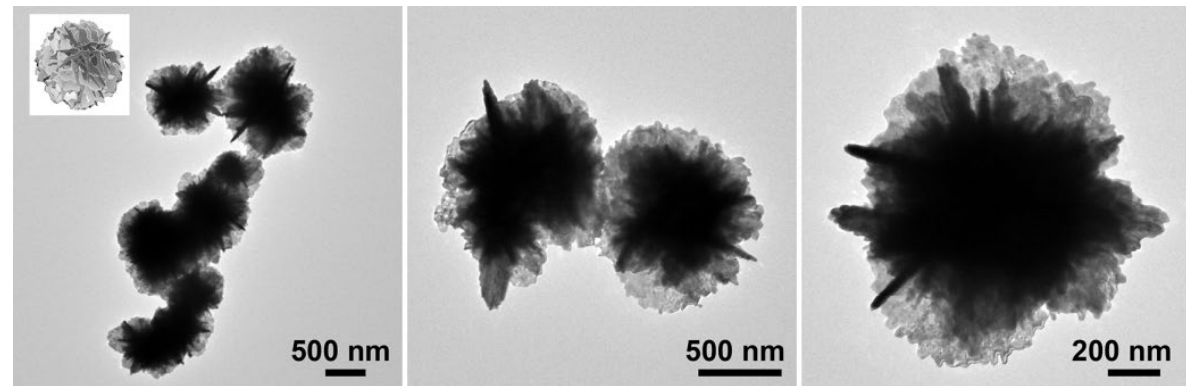

Figure S5. TEM images of $\mathrm{PdCu}$-Flower under different magnifications. 


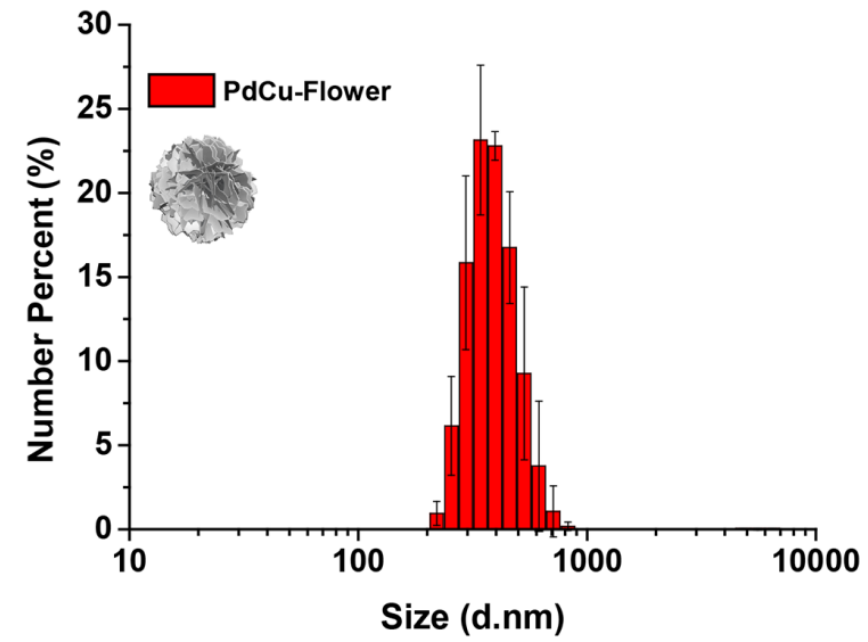

Figure S6. Hydrodynamic diameters of $\mathrm{PdCu}-\mathrm{Flower}$ dispersions in water.

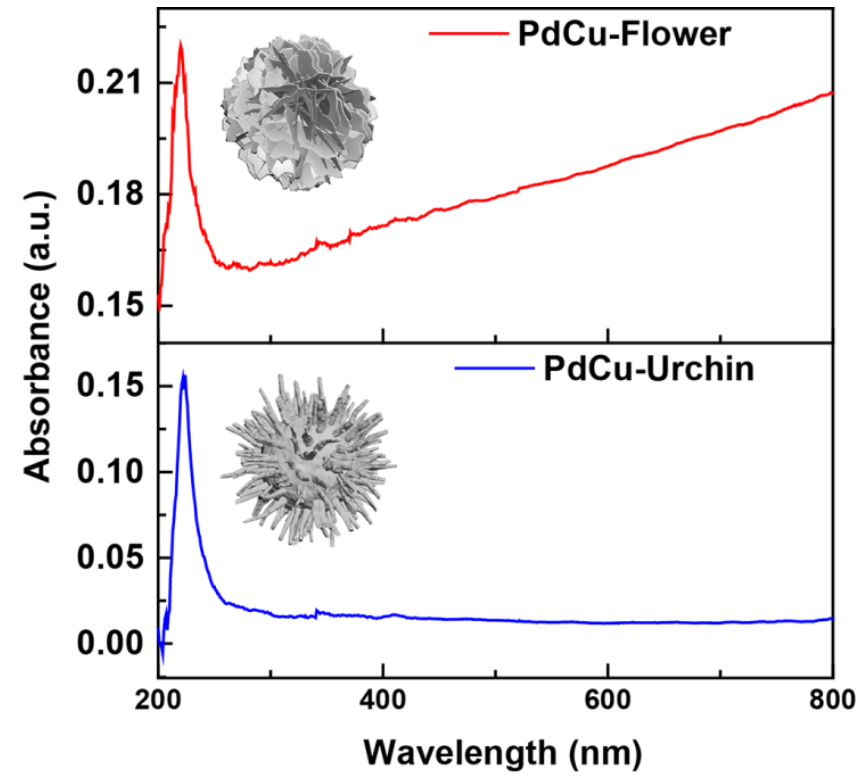

Figure S7. UV-vis absorption spectra of PdCu-Flower and PdCu-Urchin. 


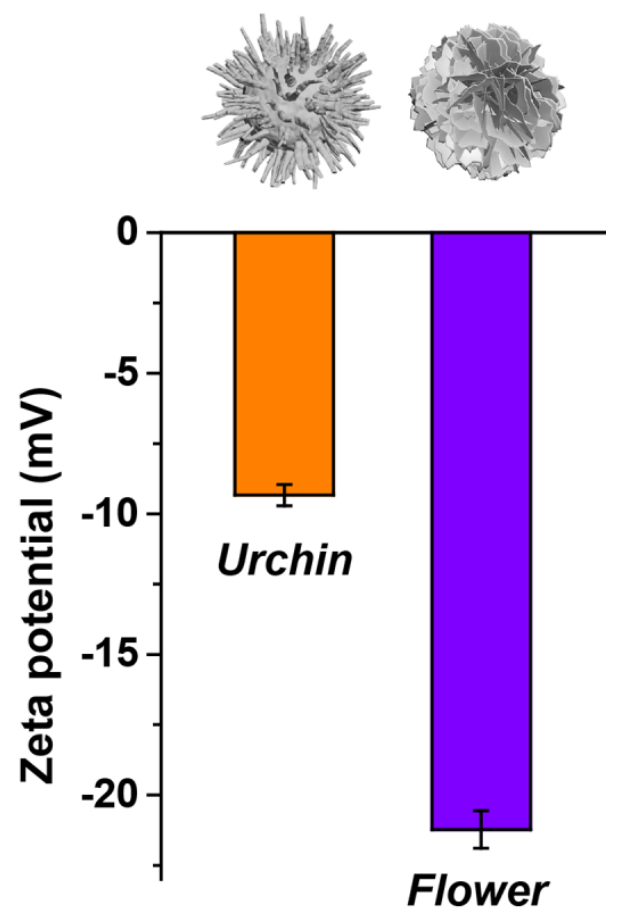

Figure S8. Zeta potentials of $\mathrm{PdCu}-\mathrm{Flower}$ and $\mathrm{PdCu}-\mathrm{Urchin}$ in water.
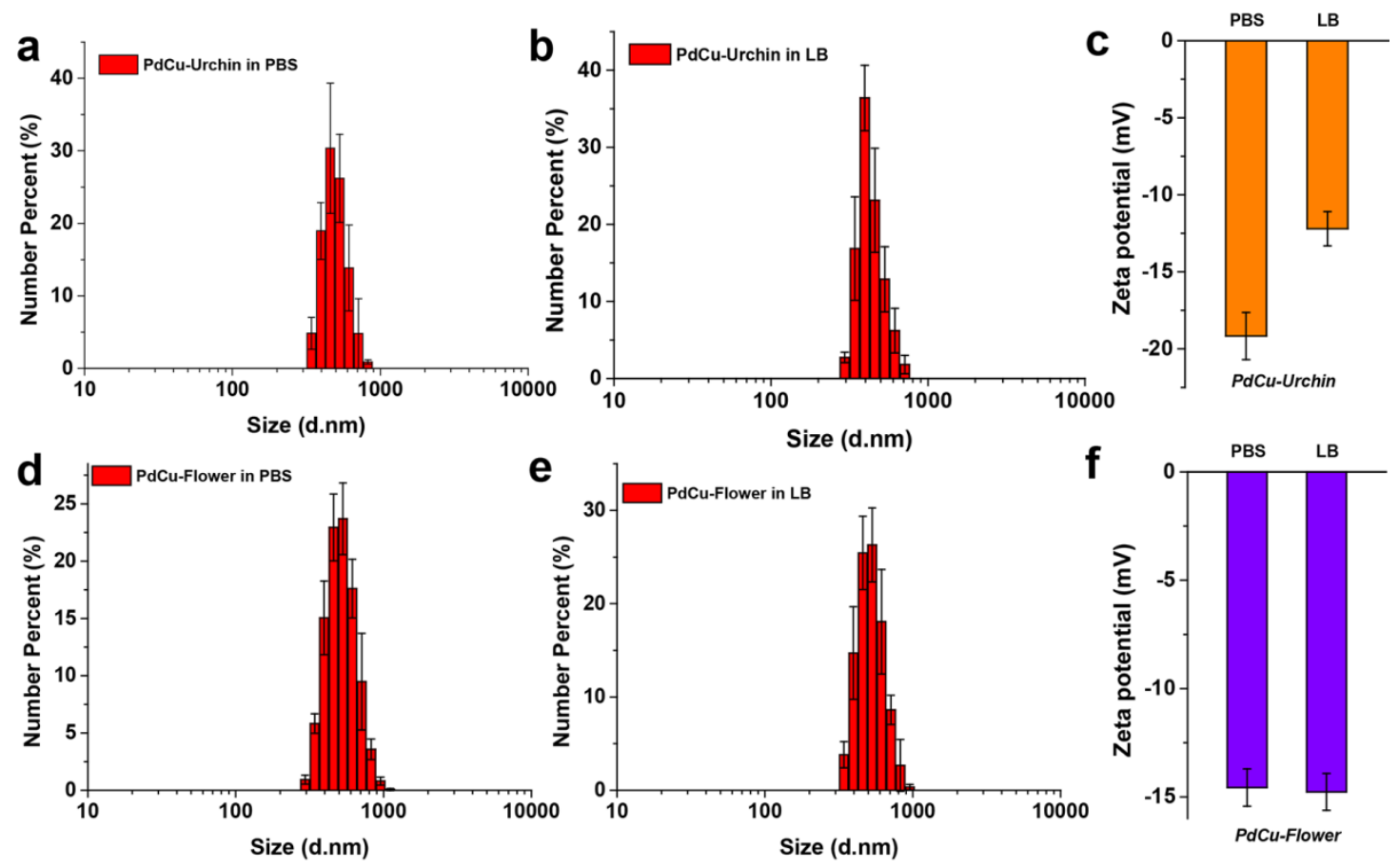

Figure S9. (a) and (b) Hydrodynamic diameters of PdCu-Urchin in PBS and LB medium. (c) Zeta potentials of PdCu-Urchin in PBS and LB medium. (d) and (e) Hydrodynamic diameters of PdCu-Flower in PBS and LB medium. (f) Zeta potentials of PdCu-Flower in PBS and LB medium. 

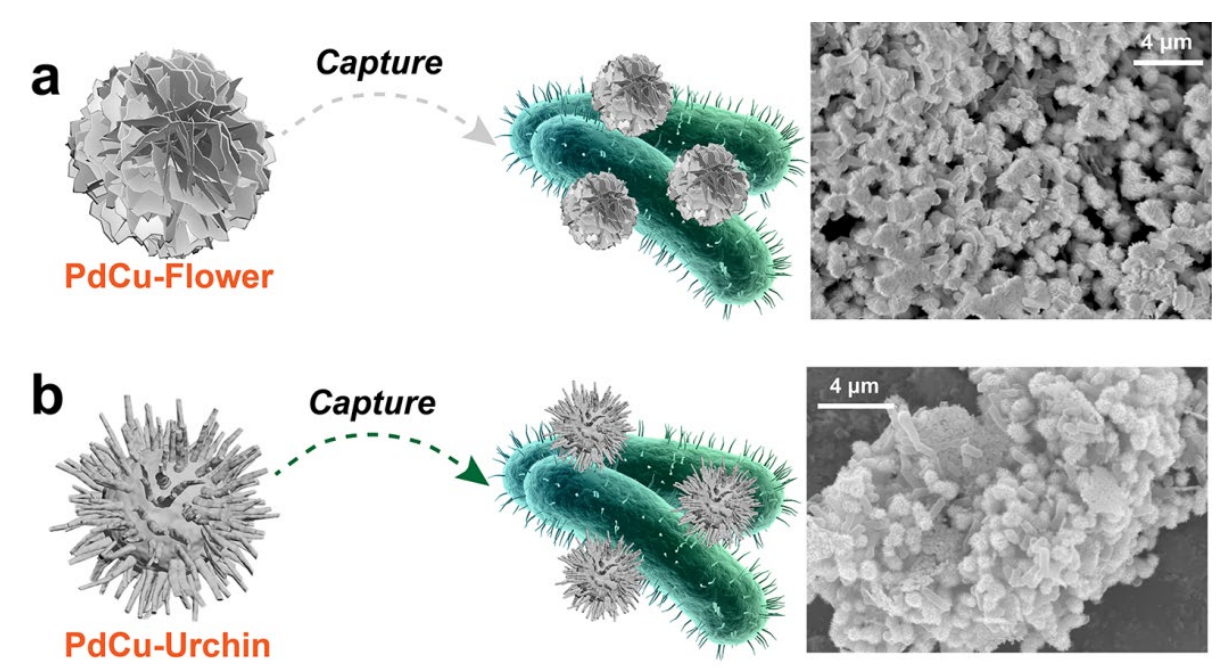

Figure S10. Typical SEM images of PdCu-Flower (a) and $\mathrm{PdCu}-U$ rchin (b) for capturing E. coli under low magnification.
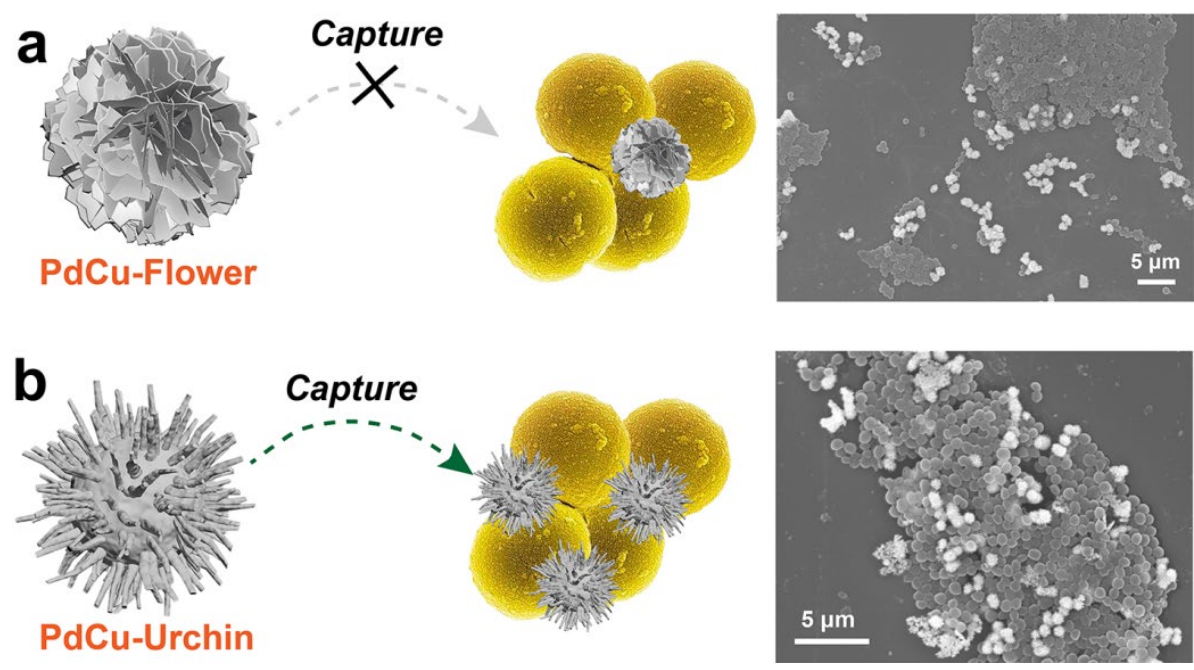

Figure S11. Typical SEM images of PdCu-Flower (a) and $\mathrm{PdCu}-\mathrm{Urchin}$ (b) for capturing $S$. aureus under low magnification. 

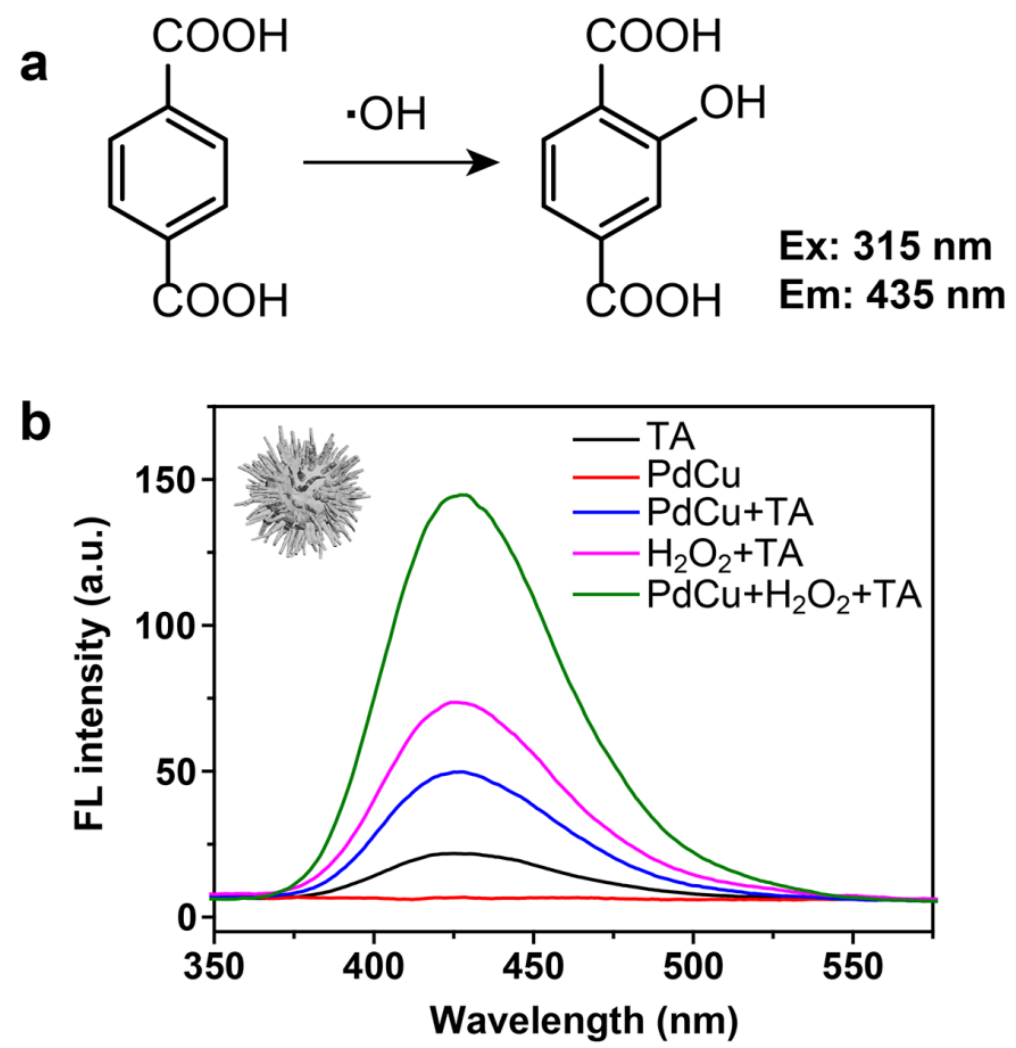

Figure S12. (a) The oxidation of terephthalic acid (TA) in acetate buffer $(0.1 \mathrm{M}, \mathrm{pH}$ 4.0), the excitation wavelength was $315 \mathrm{~nm}$. (b) Fluorescence spectra of the acetate buffer including only TA; only PdCu-Urchin; TA and PdCu-Urchin; TA and $\mathrm{H}_{2} \mathrm{O}_{2}$; TA, $\mathrm{PdCu}-\mathrm{Urchin}$ and $\mathrm{H}_{2} \mathrm{O}_{2}$ after $12 \mathrm{~h}$ reaction at $37{ }^{\circ} \mathrm{C}$. The concentrations of $\mathrm{TA}, \mathrm{H}_{2} \mathrm{O}_{2}$ and $\mathrm{PdCu}-U \mathrm{rchin}$ were $0.5 \mathrm{mM}, 1 \mathrm{mM}$ and $50 \mu \mathrm{g} / \mathrm{mL}$, respectively. 
a

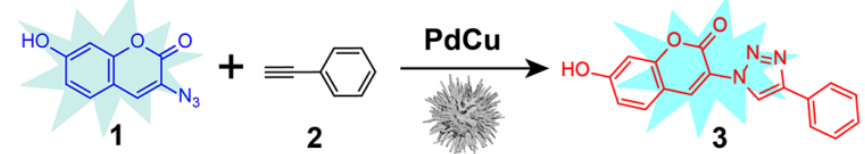

b

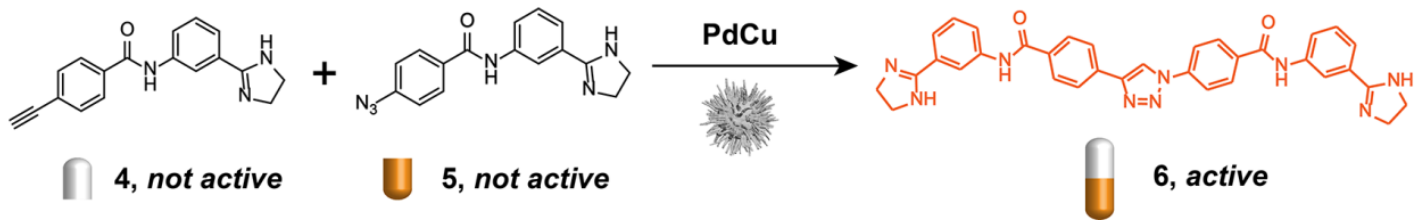

Figure S13. (a) Schematic diagram of the fluorescent product 3 produced by 1 and 2 through the click reaction. (b) Schematic diagram of the active molecule 6 produced by 4 and 5 through the click reaction
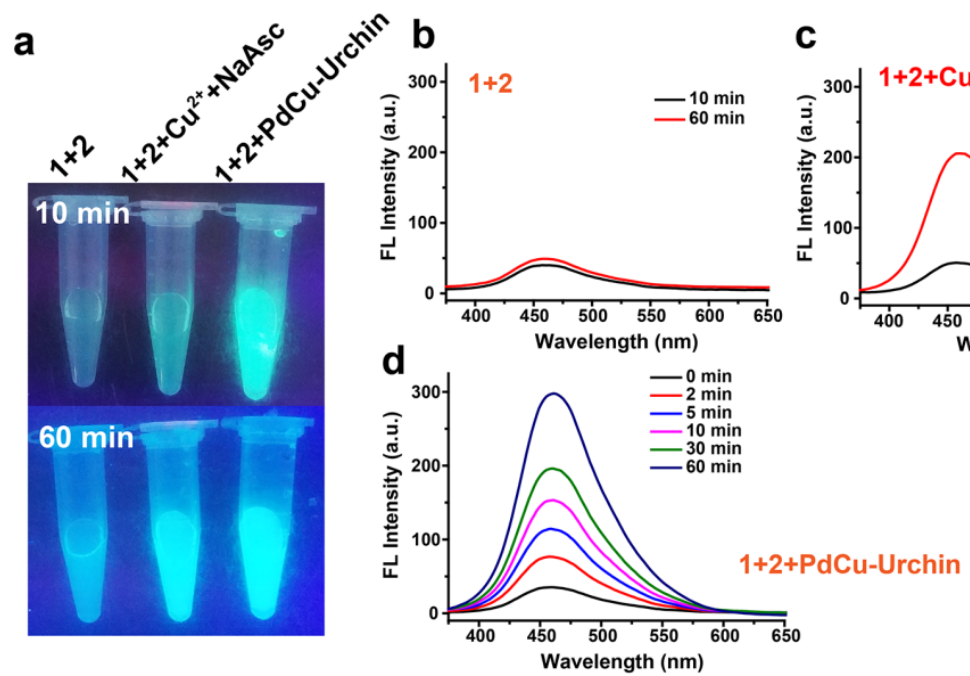

Figure S14. (a) Photographs of the reaction mixtures in different time. (b) Fluorescence spectra of the reaction mixture without catalyst. (c) Fluorescence spectra of the reaction mixture with $\mathrm{Cu}^{2+}(100 \mu \mathrm{M})$-NaAsc $(500 \mu \mathrm{M})$ catalyst. (d) Fluorescence spectra of the reaction mixture the PdCu-urchin $\left(100 \mu \mathrm{g} \cdot \mathrm{mL}^{-1}\right)$ different reaction times $(0-60 \mathrm{~min})$. The concentrations of 1,2 were $80 \mu \mathrm{M}$. 


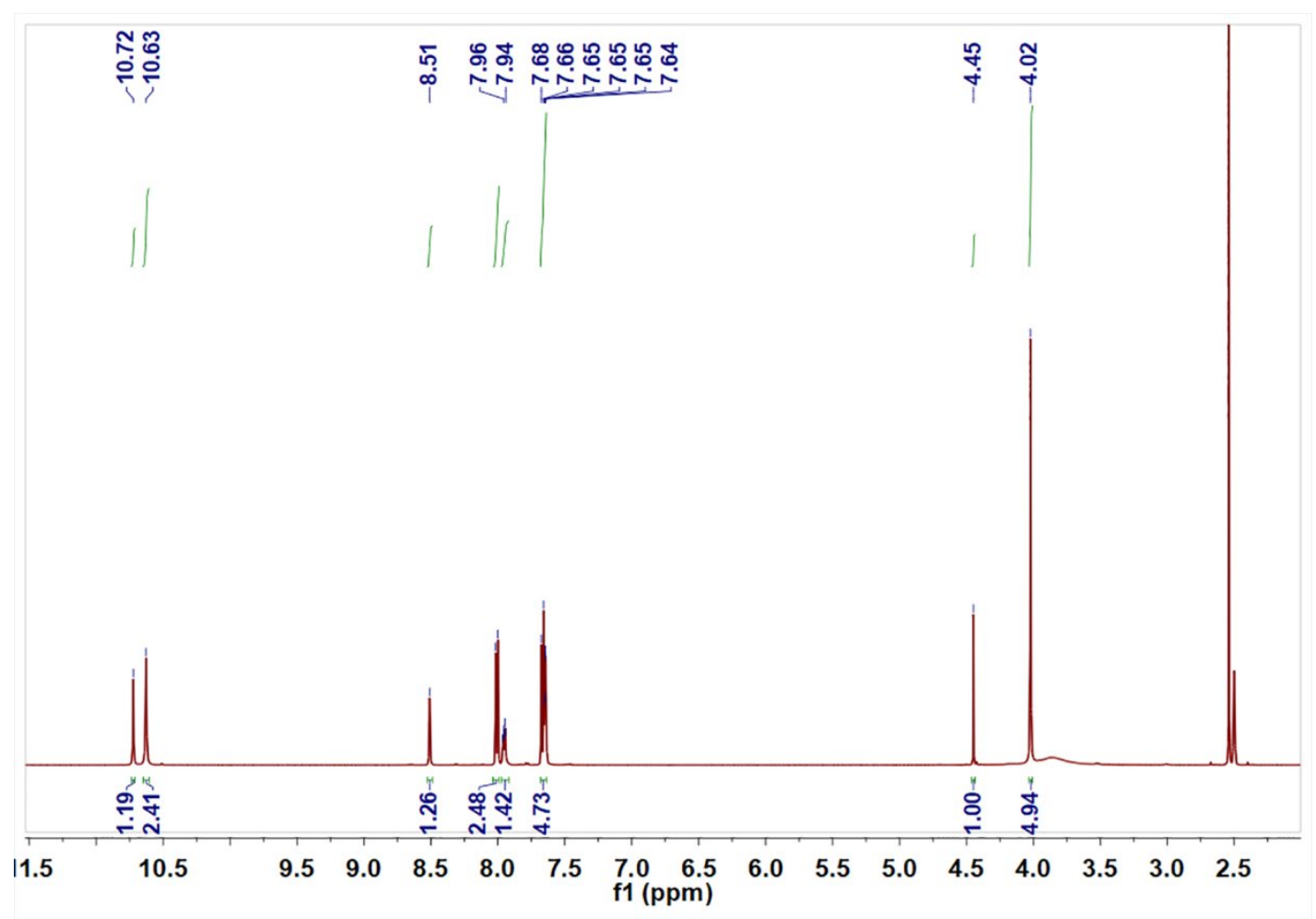

$\begin{array}{lllll}\text { Figure } & \text { S15. } & { }^{1} \mathrm{HNMR} & \text { The } & \text { of }\end{array}$ (3-(4-ethynylbenzamido)phenyl)-4,5-dihydro-1H-imidazole (compound 4$)$ in $\mathrm{CDCl}_{3}$

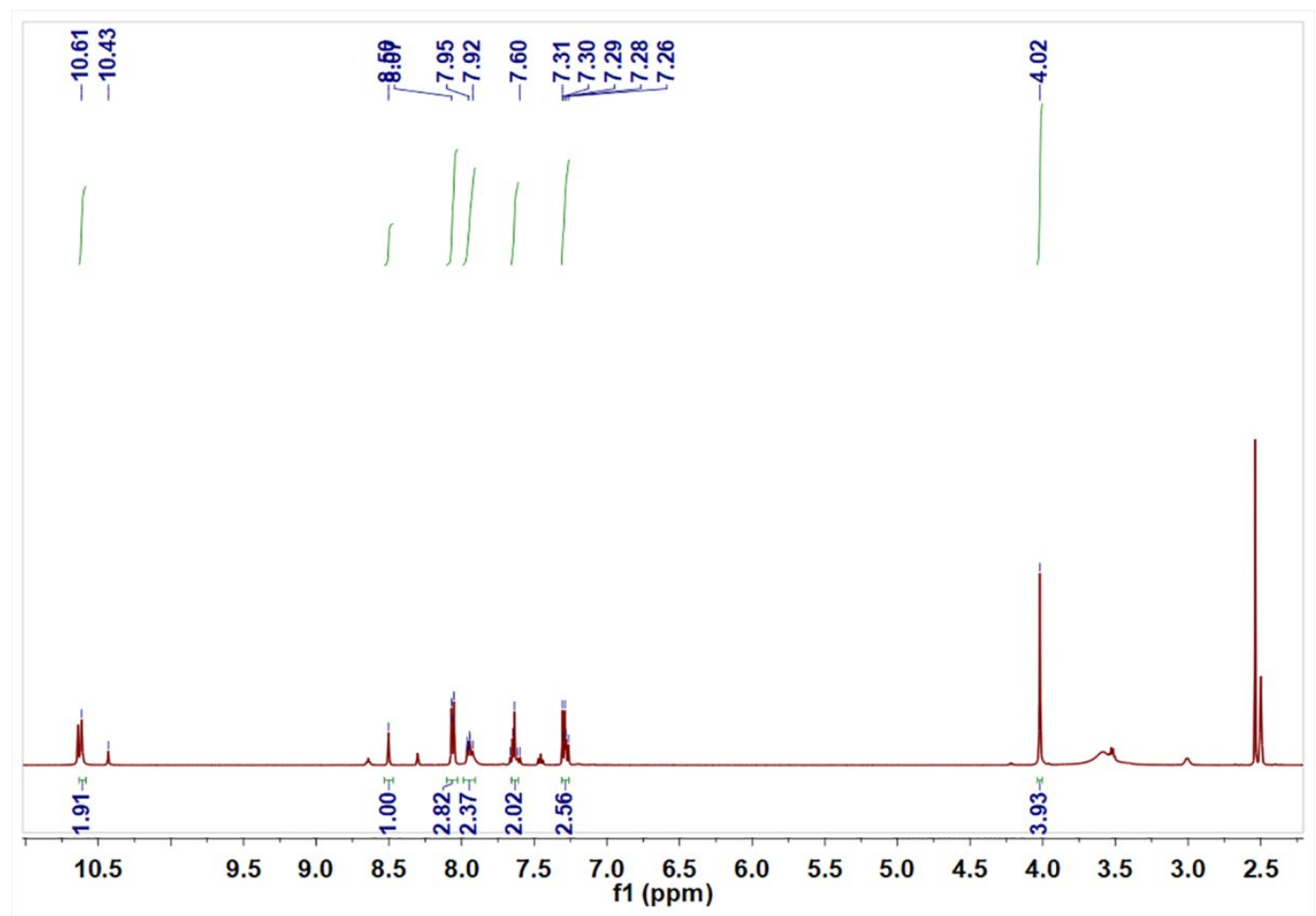


Figure S16. The ${ }^{1}$ HNMR $\quad$ spectrum

(3-(4-azidobenzamido)phenyl)-4,5-dihydro-1H-imidazole (compound 5) in $\mathrm{CDCl}_{3}$.

Liquid chromatography-mass spectrometry analysis molecule 6 generation

For LC/MS analysis. The concentrations of 4 (290.12790) and 5 (307.12929) were $100 \mu \mathrm{g} / \mathrm{mL}, \mathbf{P d C u}-$ Urchin concentration were about $100 \mu \mathrm{g} / \mathrm{mL}$. The sample was reacted in a mix solution of LB medium and DMF (4:1). The results showd that the inactive $\mathbf{4}$ and $\mathbf{5}$ precursor molecules can be catalyzed by $\mathbf{P d C u}$-Urchin to generate active molecule 6 (596.25061). 


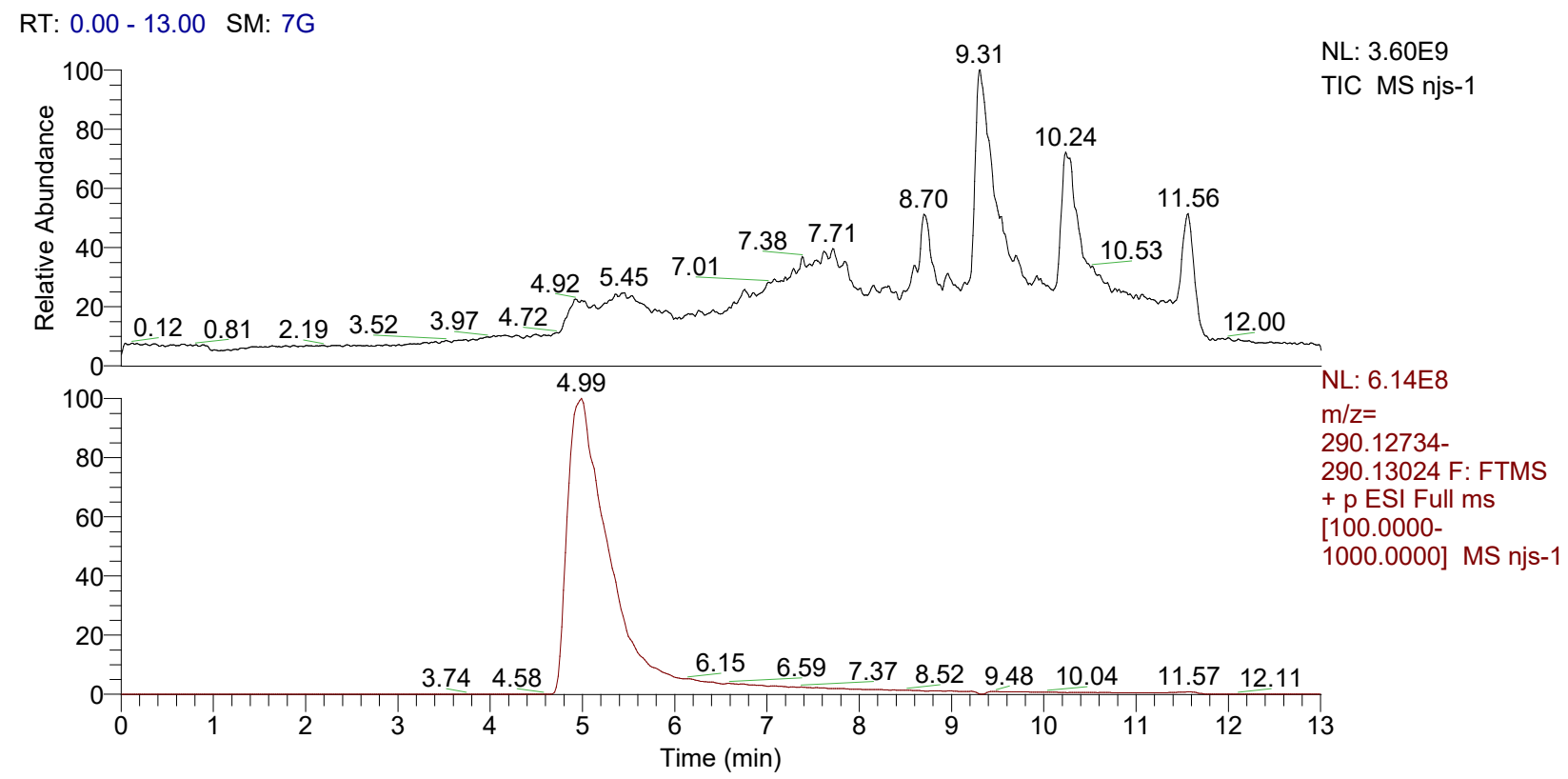

njs-1 \#491-503 RT: 4.95-5.07 AV: $7 \quad$ NL: 5.31E8

T: FTMS + p ESI Full ms [100.0000-1000.0000]

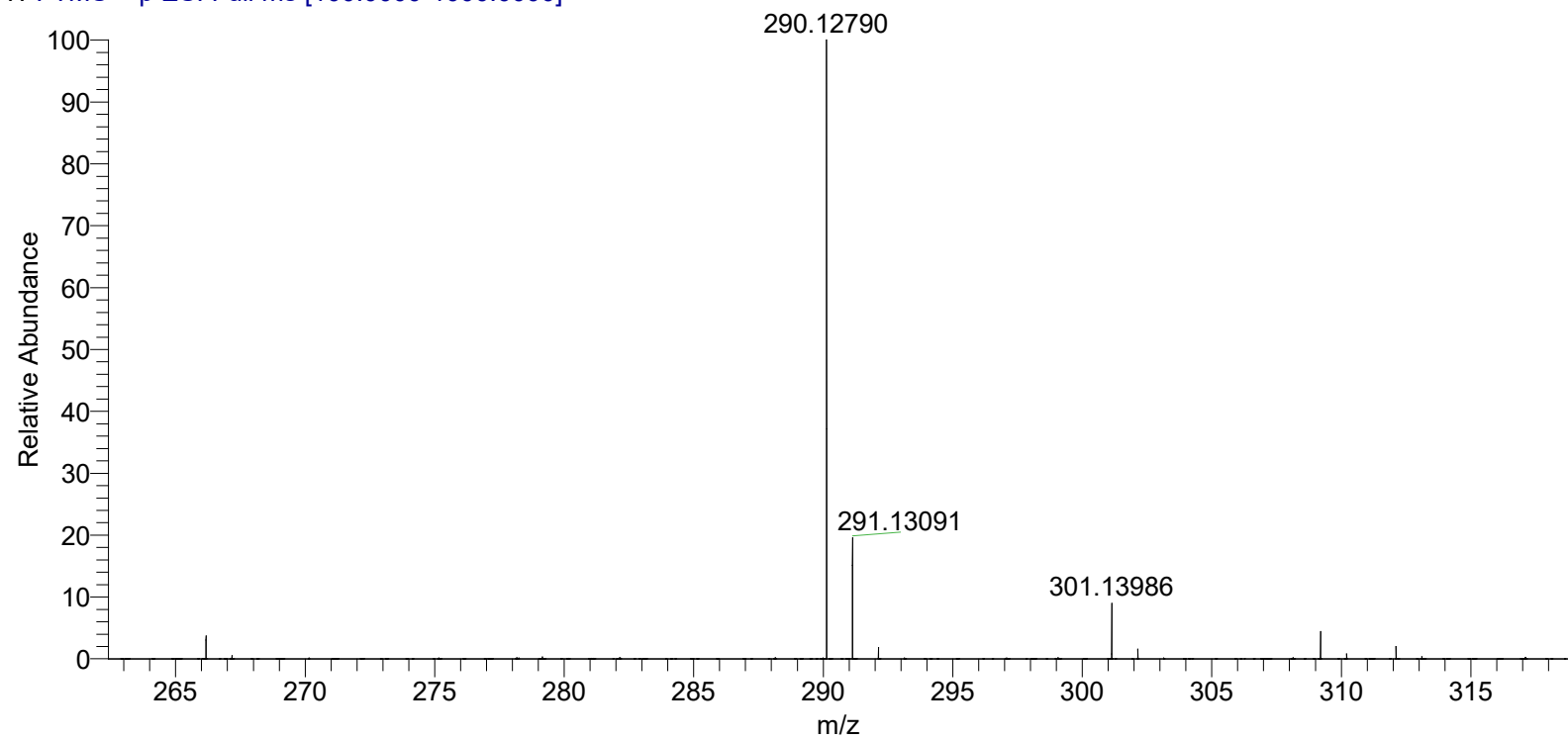

Figure S17. LC-MS analysis of precursor molecules 4 and 5 in a mixed solution of LB medium and DMF (4:1) in the presence of PdCu-Urchin. The results showed the presence of precursor molecule 4 (290.12790) in the mixed solution. 
RT: $0.00-13.00$ SM: $7 G$

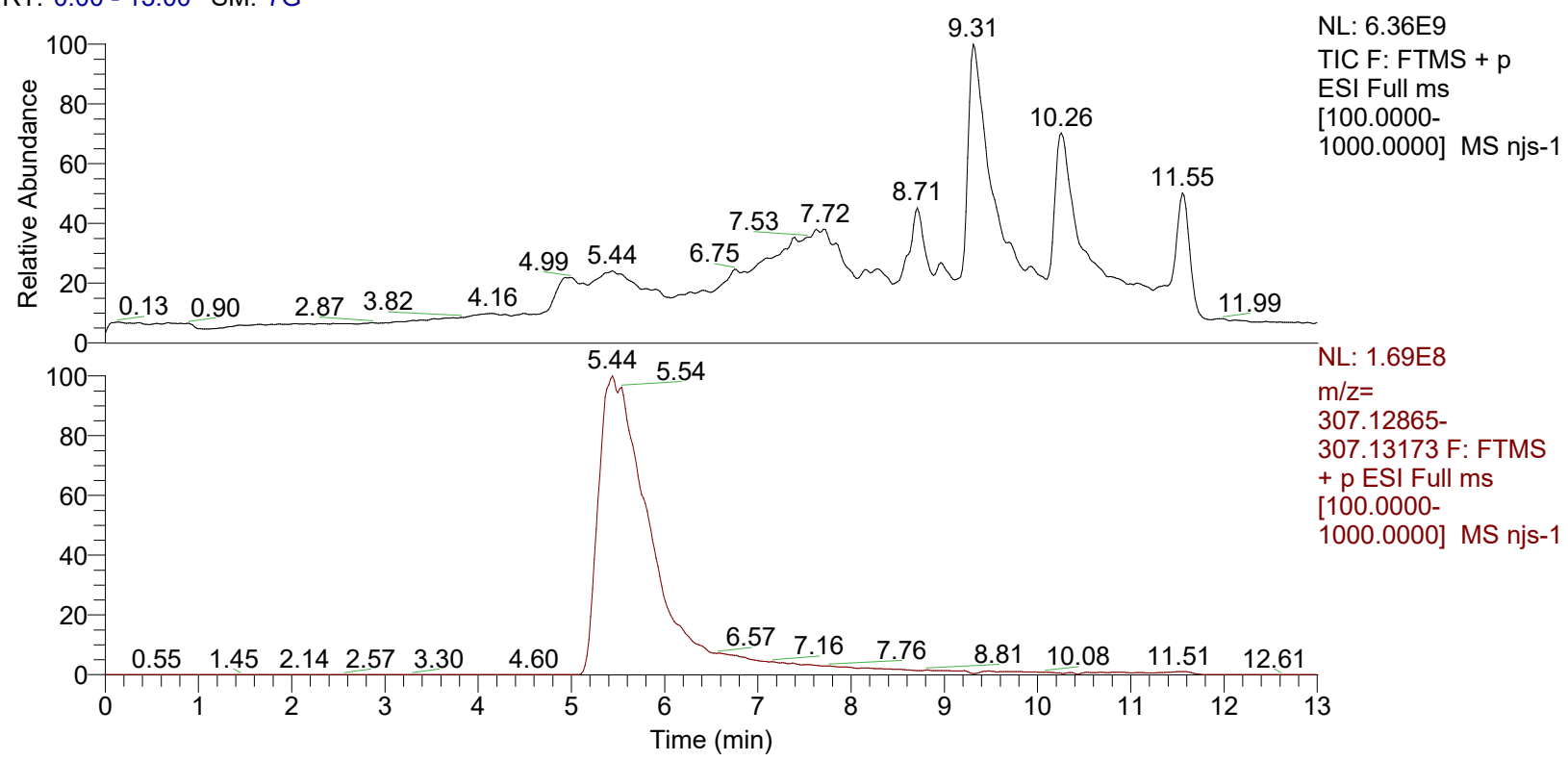

njs-1 \#561-569 RT: 5.64-5.71 AV: 5 NL: 1.21E8

T: FTMS + p ESI Full ms [100.0000-1000.0000]

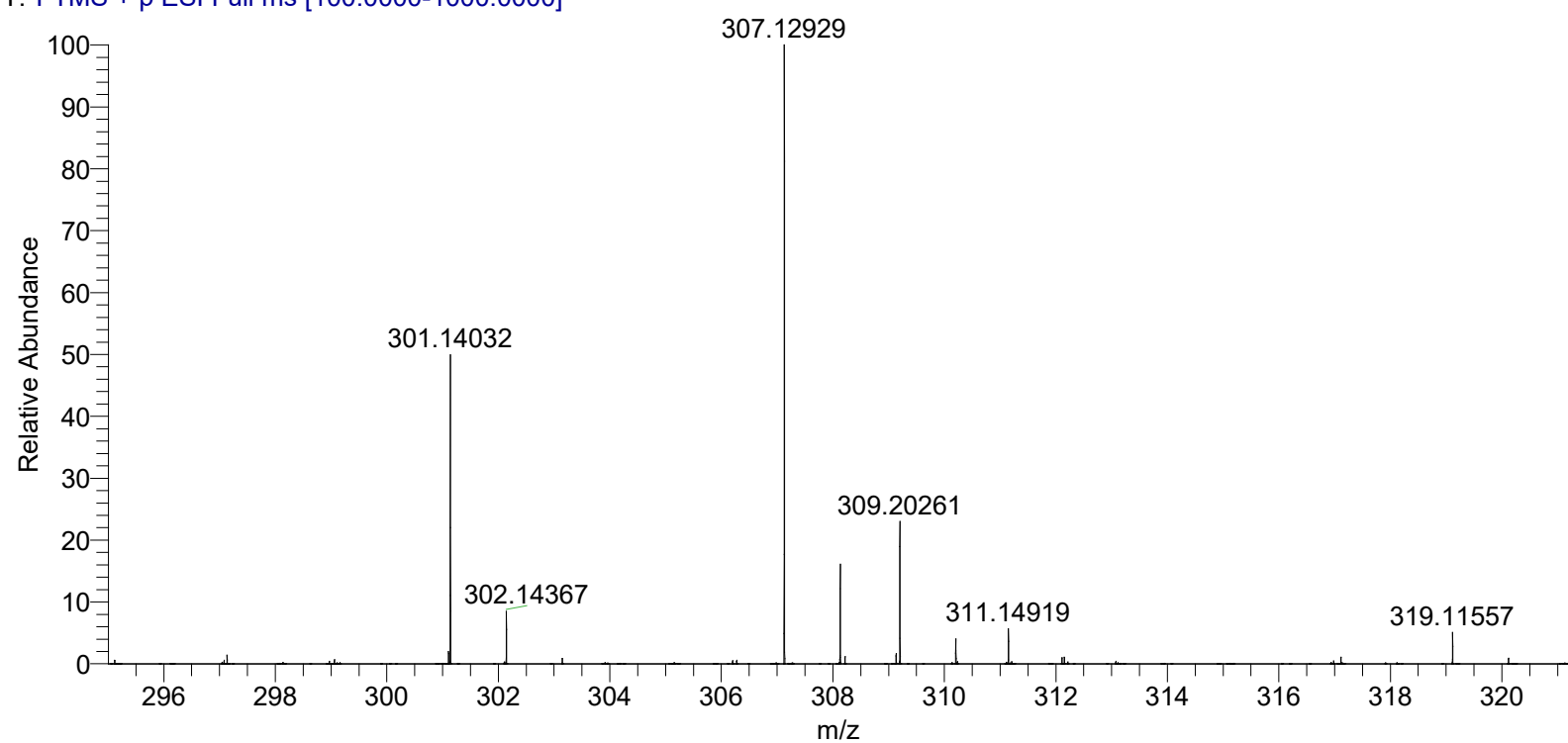

Figure S18. LC-MS analysis of precursor molecules 4 and 5 in a mixed solution of LB medium and DMF (4:1) in the presence of PdCu-Urchin. The results showed the presence of precursor molecule $\mathbf{5}(\mathbf{3 0 7 . 1 2 9 2 9})$ in the mixed solution. 
RT: $0.00-13.00$ SM: $7 G$

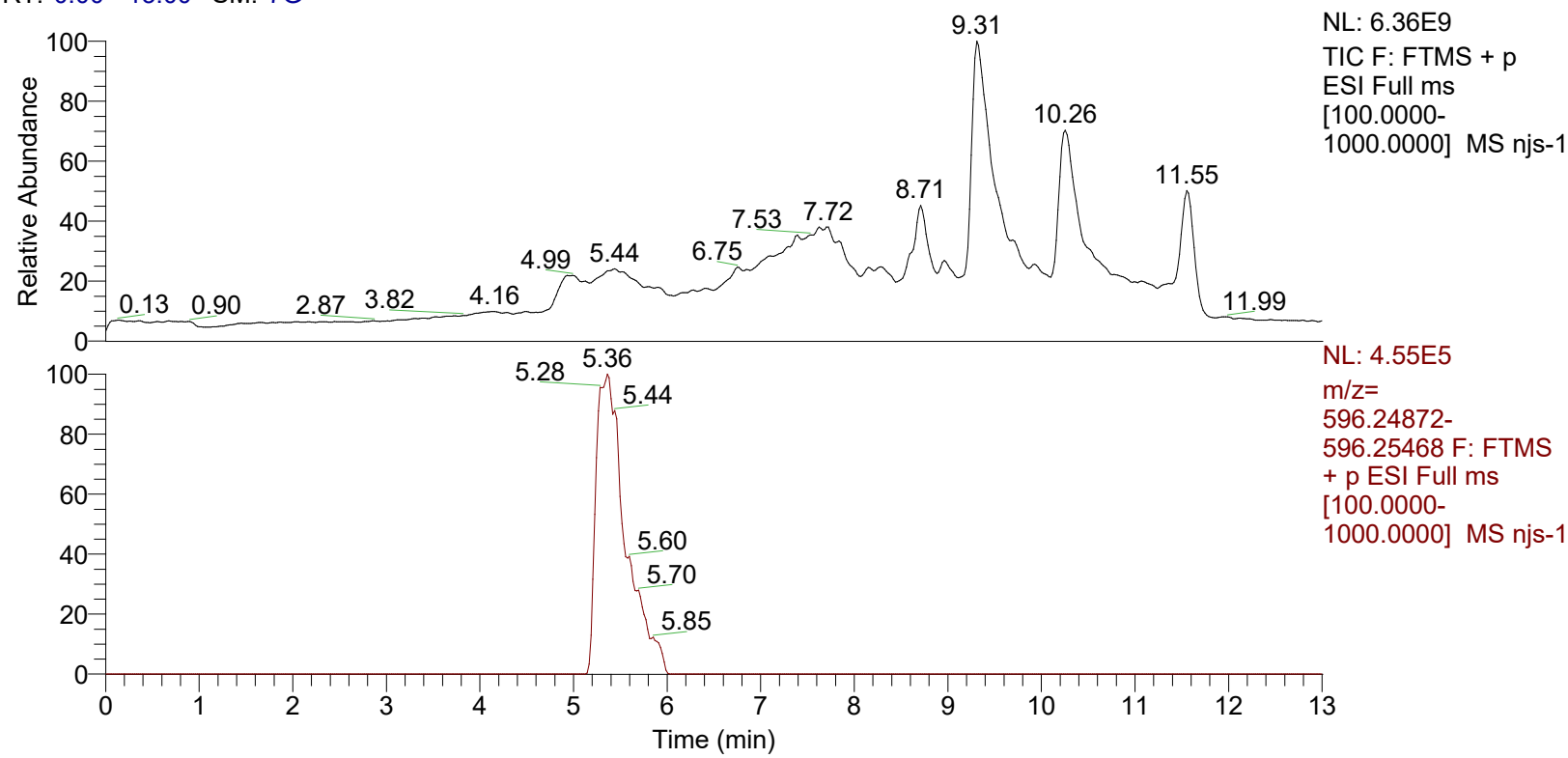

njs-1 \#525-536 RT: 5.28-5.38 AV: 6 NL: 4.18E5

T: FTMS + p ESI Full ms [100.0000-1000.0000]

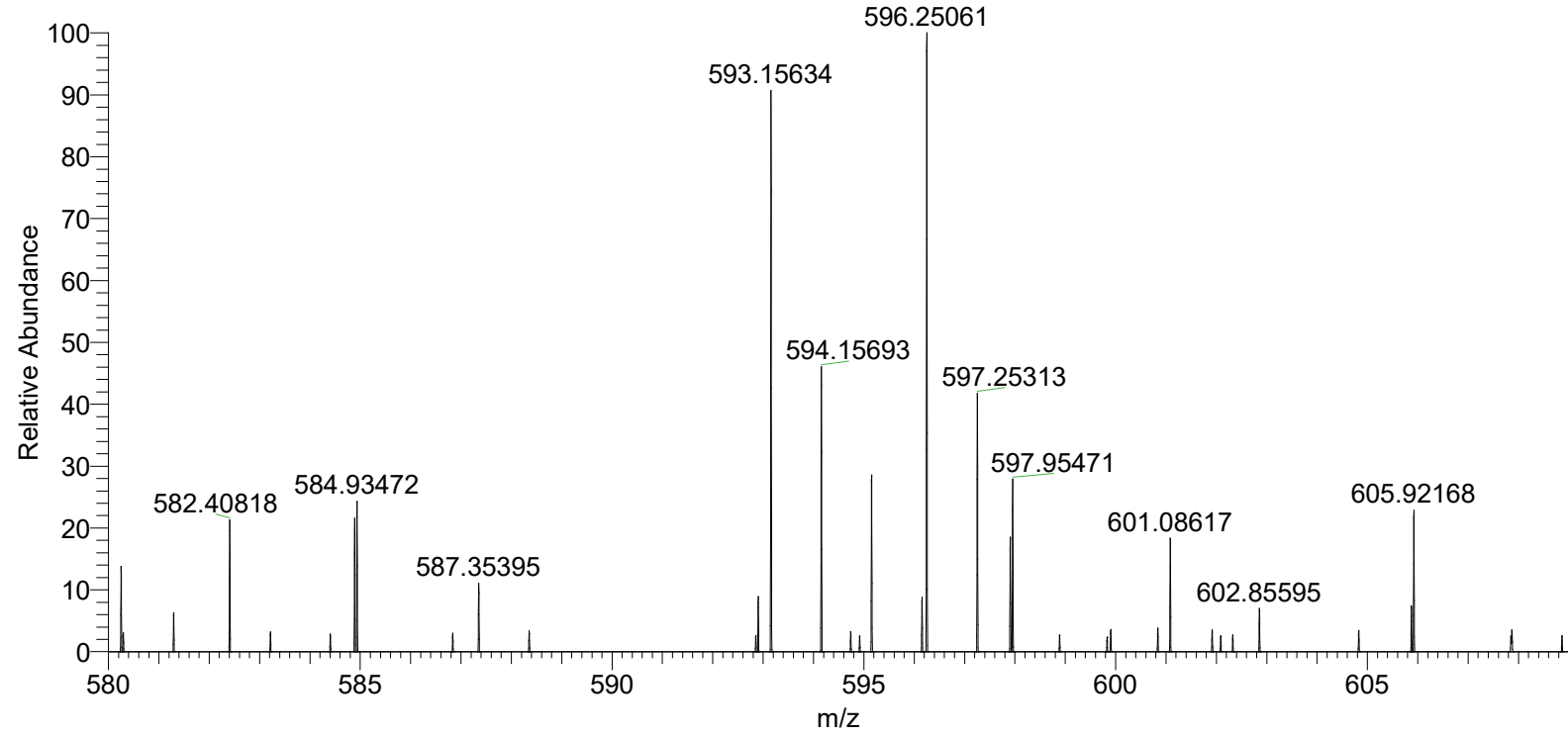

Figure S19. LC-MS analysis of precursor molecules 4 and 5 in a mixed solution of LB medium and DMF (4:1) in the presence of PdCu-Urchin. The results showed that the inactive 4 and 5 precursor molecules can be catalyzed by $\mathrm{PdCu}-U$ rchin to generate active molecule 6 (596.25061). 

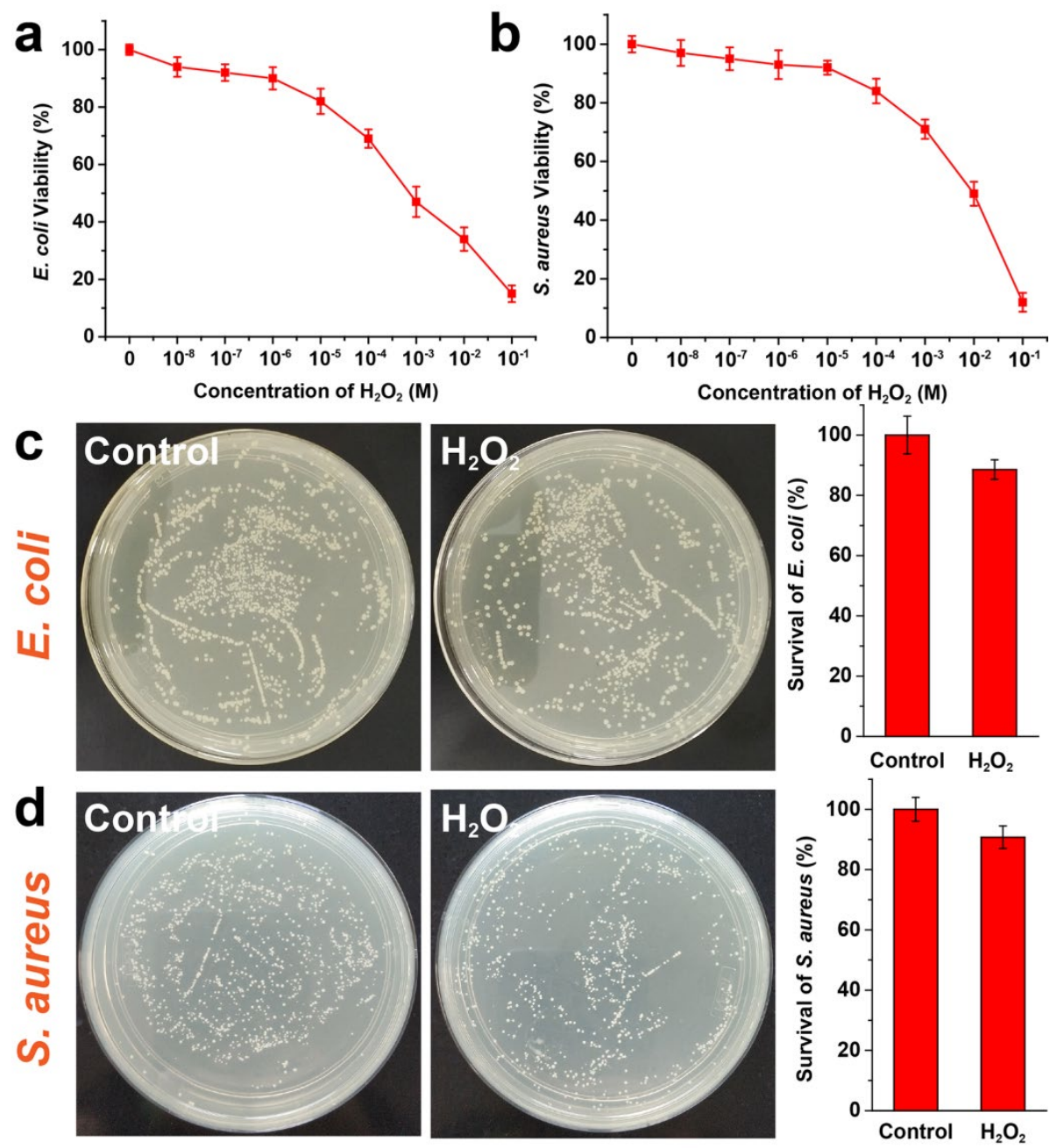

Figure S20. (a) Relative bacterial viabilities of E. coli (a) and S. aureus (b) treated with different concentrations of $\mathrm{H}_{2} \mathrm{O}_{2}$. (c) and (d) The evaluation of E. coli and $S$. aureus growth by spread plate, and the corresponding bar graph of the percentage of surviving bacteria of $E$. coli and $S$. aureus. The concentration of $\mathrm{H}_{2} \mathrm{O}_{2}$ was $100 \mu \mathrm{M}$. 


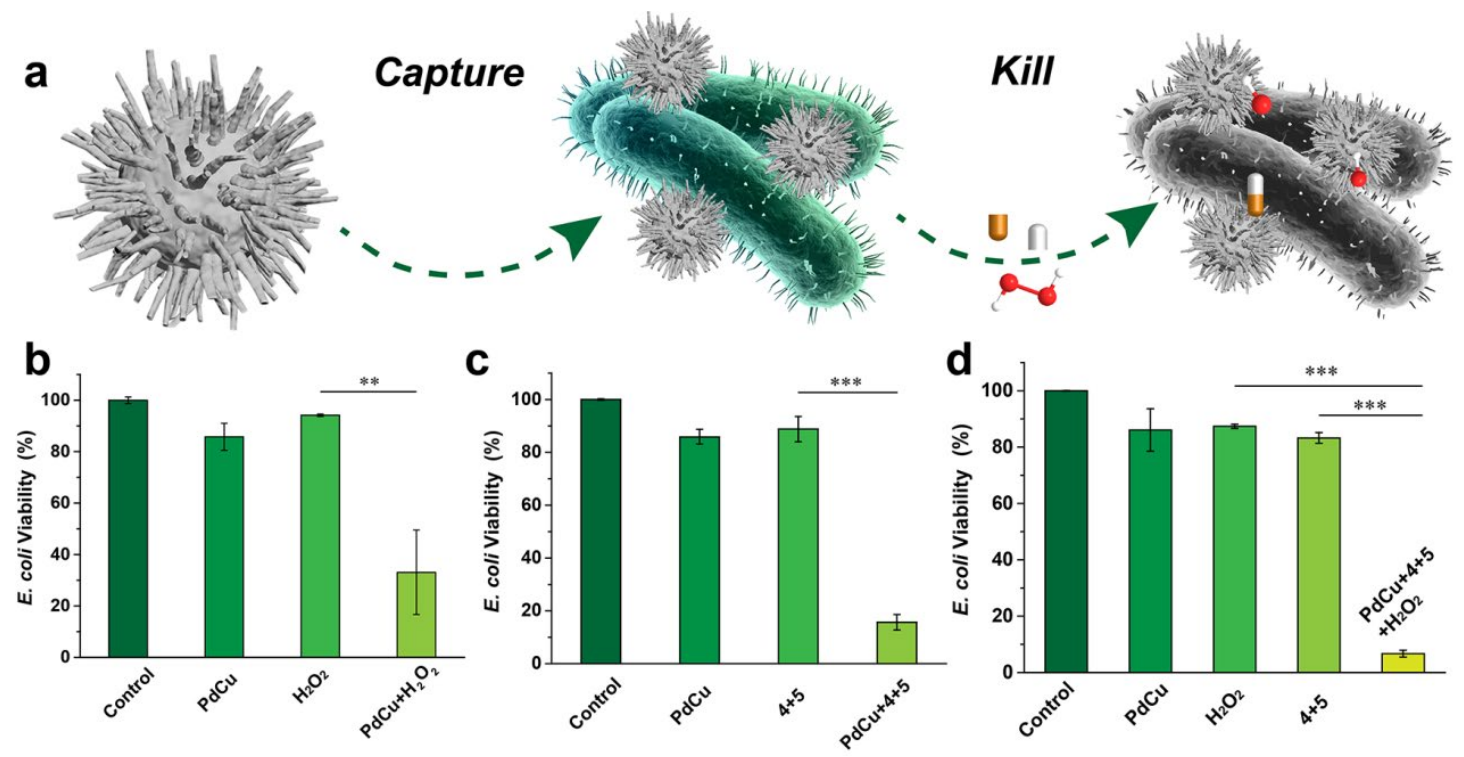

Figure S21. (a) Schematic diagram of $\mathrm{PdCu}$-Urchin capturing and killing E. coli. (b-d) Growth-inhibition assay was conducted for evaluating the antibacterial effect towards E. coli in LB medium with different treatments.

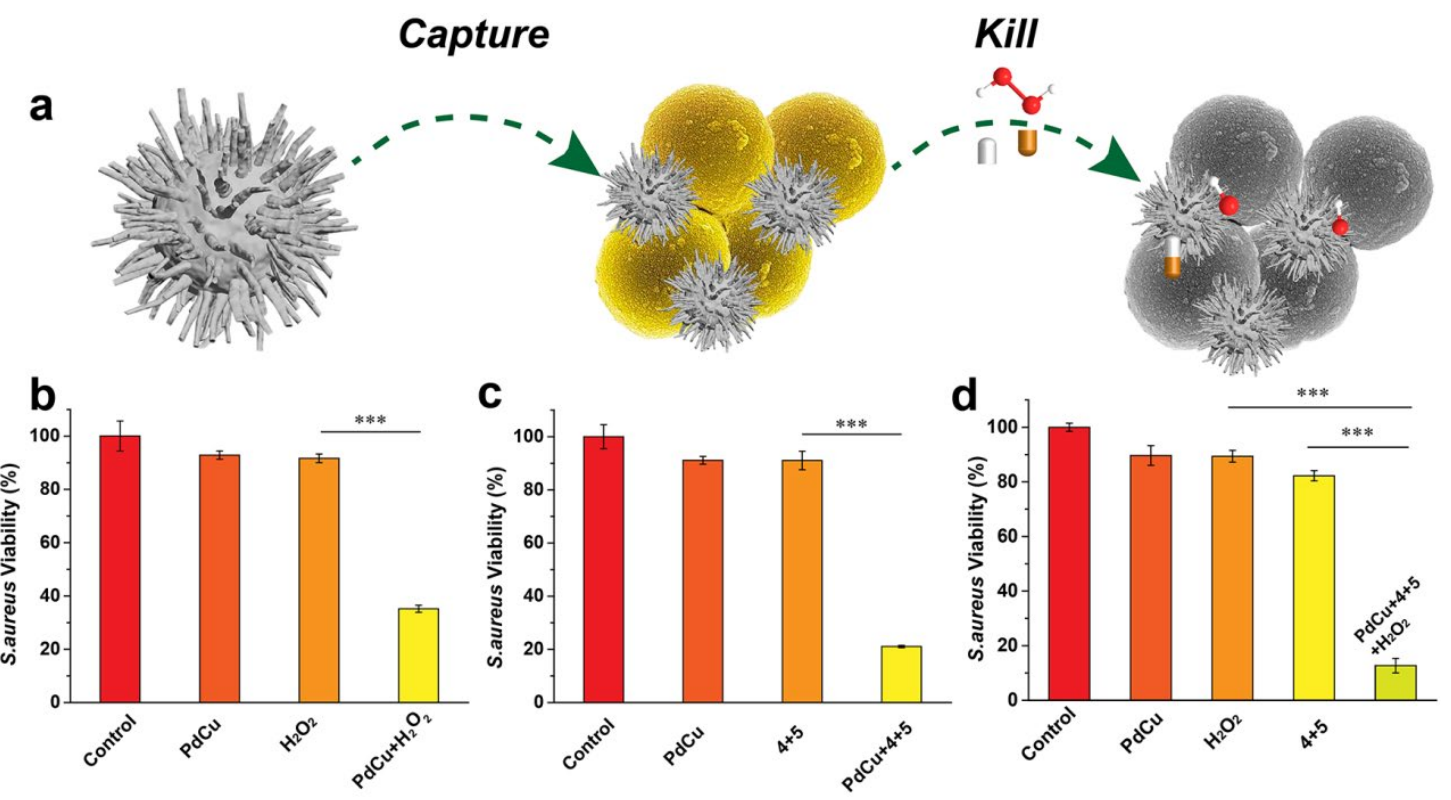

Figure S22. (a) Schematic diagram of $\mathrm{PdCu}-U$ rchin capturing and killing $S$. aureus. (b-d) Growth-inhibition assay was conducted for evaluating the antibacterial effect towards $S$. aureus in LB medium with different treatments. 


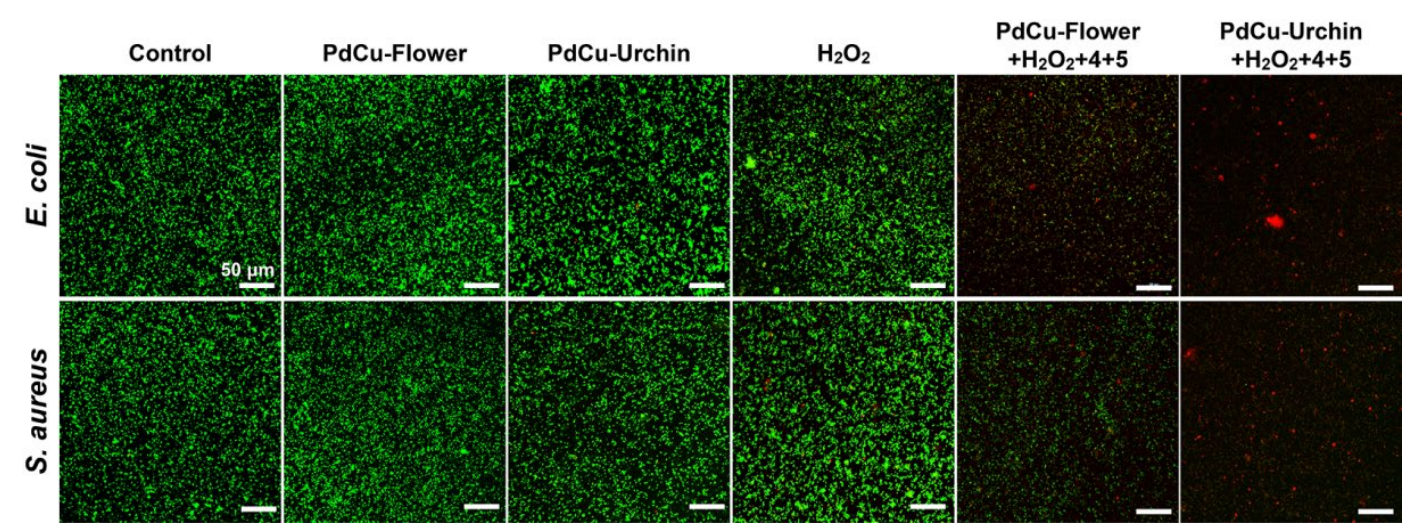

Figure S23. Live-dead confocal images of E. coli and $S$. aureus treated with different groups. Viable bacteria were stained green with FDA, and dead bacteria were stained red with PI

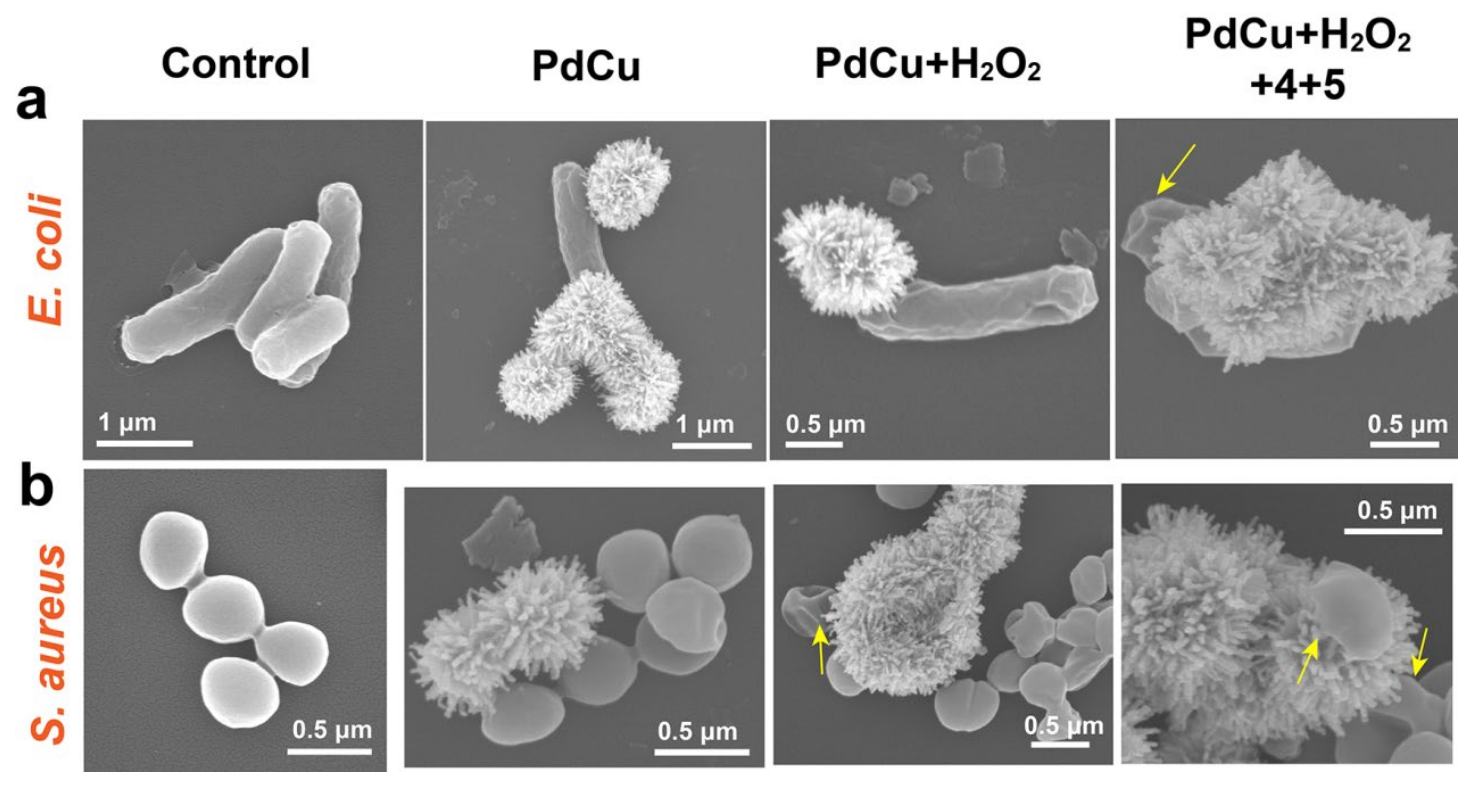

Figure S24. Typical SEM images for assessing the morphological damage to (a) $E$. coli and (b) S. aureus with different treatments in high magnification. 

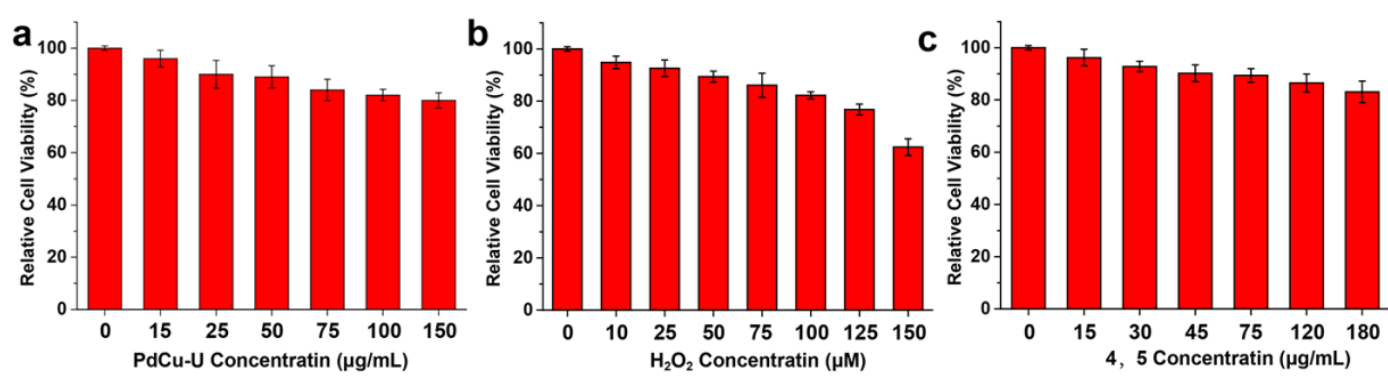

Figure S25. Cell viability of $3 \mathrm{~T} 3$ cells after $24 \mathrm{~h}$ incubation with different concentrations $\mathrm{PdCu}$-Urchin nanoparticles (a), $\mathrm{H}_{2} \mathrm{O}_{2}$ (b), $4+5$ (c).

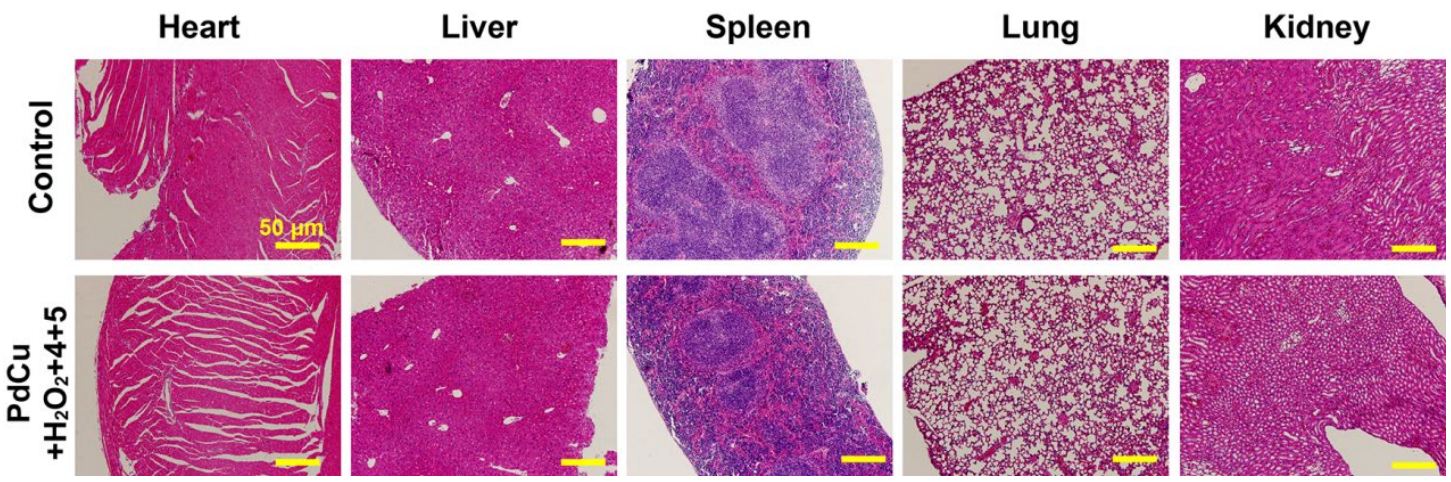

Figure S26. Cytotoxic effect caused by $\mathrm{PdCu}$-Urchin in major organs (heart, liver, spleen, lung, and kidney) after 5 days treatment with (a) PBS, (b) PdCu-Urchin, 50 $\mu \mathrm{g} / \mathrm{mL}$. 


\section{References}

1. Chen, Y.; Niu, H.-J.; Feng, Y.-G.; Wu, J.-H.; Wang, A.-J.; Huang, H.; Feng, J.-J. Three-dimensional hierarchical urchin-like PdCuPt nanoassembles with zigzag branches: A highly efficient and durable electrocatalyst for formic acid oxidation reaction. Appl. Surf. Sci. 2020, 510, 145480.

2. Zhu, W.; Wang, Y.; Li, K.; Gao, J.; Huang, C. H.; Chen, C. C.; Ko, T. P.; Zhang, Y.; Guo, R. T.; Oldfield, E. Antibacterial drug leads: DNA and enzyme multitargeting. J. Med. Chem. 2015, 58 (3), 1215-27.

3. Bai, Y.; Feng, X.; Xing, H.; Xu, Y.; Kim, B. K.; Baig, N.; Zhou, T.; Gewirth, A. A.; Lu, Y.; Oldfield, E.; Zimmerman, S. C. A Highly Efficient Single-Chain Metal-Organic Nanoparticle Catalyst for Alkyne-Azide "Click" Reactions in Water and in Cells. J. Am. Chem. Soc. 2016, 138 (35), 11077-11080. 